\title{
A gramática como ferramenta para a construção de texto: relato de uma experiência do PIBID
}

\author{
Magda Bahia Schlee
}

UERJ

O PIBID, Programa Institucional de Bolsa de Iniciação à Docência, é uma iniciativa para o aperfeiçoamento e a valorização da formação de professores para a educação básica. O programa concede bolsas a alunos de licenciatura participantes de projetos de iniciação à docência desenvolvidos por Instituições de Educação Superior (IES) em parceria com escolas de educação básica da rede pública de ensino.

Os diversos subprojetos que compõem o PIBID têm como objetivo geral promover a inserção dos estudantes no contexto das escolas públicas desde o início da sua formação acadêmica, para que desenvolvam atividades didático-pedagógicas sob orientação de um docente da licenciatura e de um professor da escola.

Dentre os objetivos específicos, o Ministério da Educação, via Fundação Capes, cita os seguintes:

- Incentivar a formação de docentes em nível superior para a educação básica;

- contribuir para a valorização do magistério;

- elevar a qualidade da formação inicial de professores nos cursos de licenciatura, promovendo a integração entre educação superior e educação básica;

- inserir os licenciandos no cotidiano de escolas da rede pública de educação, proporcionando-lhes oportunidades de criação e participação em experiências metodológicas, tecnológicas e práticas docentes de caráter inovador e interdisciplinar que busquem a superação de problemas identificados no processo de ensino-aprendizagem;

- incentivar escolas públicas de educação básica, mobilizando seus professores como coformadores dos futuros docentes e tornando-as protagonistas nos processos de formação inicial para o magistério; e

- contribuir para a articulação entre teoria e prática necessárias à formação dos docentes, elevando a qualidade das ações acadêmicas nos cursos de licenciatura.

Para participar do Programa de iniciação à Docência, Instituições de Educação Superior interessadas devem apresentar a Capes seus projetos de iniciação à docência conforme os editais de seleção publicados. Podem se candidatar IES públicas e privadas com e sem fins lucrativos que oferecem cursos de licenciatura. 
As instituições aprovadas pela Capes recebem cotas de bolsas e recursos de custeio e capital para o desenvolvimento das atividades do projeto. Os bolsistas do PIBID são escolhidos por meio de seleções promovidas por cada IES.

O presente relato tem como objetivo narrar a experiência de um dos subprojetos vinculados ao PIBID, mais especificamente, o subprojeto de Língua Portuguesa de uma instituição de ensino superior pública, a Universidade do Estado do Rio de Janeiro, UERJ, unidade Maracanã. O subprojeto teve início em 2014 e conta com a participação de três coordenadores, sete supervisores, e quarenta e um bolsistas. O subprojeto está alocado em duas escolas da cidade do Rio de Janeiro, uma municipal, responsável pelo primeiro e segundo ciclos do ensino fundamental, a Escola Municipal Leão Velloso; e outra, estadual, responsável pelo ensino médio, o Colégio Estadual Antônio Prado Júnior.

O subprojeto tem trabalhado em duas frentes. No ensino fundamental, as ações realizadas pelo subprojeto de Língua Portuguesa visam ao levantamento do perfil sociolinguístico dos alunos a partir de suas crenças e atitudes como forma de levar ao conhecimento desses discentes as noções de correção e adequação linguística, variação e conservação, norma-padrão, conceitos tão relevantes no processo de ensinoaprendizagem de uma língua. Já no ensino médio, o foco tem sido a gramática como forma de instrumentalizar o ensino da leitura e produção de textos de diferentes gêneros.

O presente relato, contudo, ficará centrado nas observações e atividades desenvolvidas pelos bolsistas que trabalham com ensino médio, focando especificamente no ensino de gramática nas aulas de língua portuguesa e na sua importância para a produção de textos escritos. Desde o início das atividades no colégio, foi possível perceber a manutenção de uma prática pedagógica de ensino de gramática muitas vezes reducionista. De modo geral, a observação das aulas de português e a análise do material didático deixaram evidente uma ênfase na análise puramente metalinguística dos itens gramaticais em frases descontextualizadas. Os alunos do colégio eram apresentados às diferentes categorias gramaticais, aprendiam a nomeá-las e classificá-las, mas não sabiam quando deviam usá-las. Sendo assim, o discente acabava não vendo muita utilidade na gramática, uma vez que ela era estudada como objeto autônomo, independente dos usos que eles, discentes, fazem dela no seu dia a 
dia. As palavras de Travaglia (1996 p.101) espelham exatamente o que foi percebido nas aulas de língua portuguesa:

\begin{abstract}
Observa-se também uma concentração muito grande no uso de metalinguagem no ensino de gramática teórica para a identificação e classificação de categorias, relações e funções dos elementos linguísticos, o que caracterizaria um ensino descritivo, (...).
\end{abstract}

À medida que o trabalho com as turmas que integram o projeto se desenvolvia, foi possível perceber que toda a prática pedagógica descrita anteriormente refletia uma concepção que examina a linguagem como objeto autônomo, investigando a estrutura linguística independentemente do uso. Afinal, como bem observa Antunes (2003, p. 39):

Toda atividade pedagógica de ensino do português tem subjacente, de forma explícita ou apenas intuitiva, uma determinada concepção de língua (grifo do autor). Nada do que se realiza na sala de aula deixa de estar dependente de um conjunto de princípios teóricos, a partir dos quais os fenômenos linguísticos são percebidos e tudo, consequentemente se decide. Desde a definição dos objetivos, passando pela seleção dos objetos de estudo, até a escolha dos procedimentos mais corriqueiros e específicos, em tudo está presente uma determinada concepção de língua, de suas funções, de seus processos de aquisição, de uso e aprendizagem.

Assim, não seria possível mudar o tratamento dado aos fenômenos linguísticos nas aulas de português sem munir os bolsistas, professores e demais envolvidos na prática pedagógica de um aporte teórico que lhes permitisse ver a linguagem sob nova perspectiva. Se o objetivo é o de contribuir significativamente para que os alunos ampliem sua competência no uso da língua portuguesa, só uma abordagem linguística de cunho funcional seria capaz de instrumentalizar essa prática.

Tal abordagem representa, na verdade, uma oposição ao tratamento formalista dos aspectos gramaticais. Tradicionalmente, o pólo formalista caracteriza-se, em termos gerais, pelo esforço de analisar a língua como um elemento autônomo, cuja estrutura independe de seu uso em situações comunicativas reais. Segundo os formalistas, a língua não deve ser interpretada como o reflexo de um conjunto de fatos nãolinguísticos, mas como uma "unidade encerrada em si mesma, como uma estrutura sui generis" (Hjelmslev, apud Martelotta, 2003). Nessa perspectiva, a língua apresenta um caráter abstrato e estático, já que é dissociada do ato comunicativo.

O pólo funcionalista, em contrapartida, concebe a língua como um instrumento de interação social, que, como tal, não pode ser analisado como um objeto autônomo, 
mas como uma estrutura maleável, sujeita a pressões oriundas das diferentes situações comunicativas, que ajudam a determinar sua estrutura gramatical. Consequentemente, o interesse de investigação das perspectivas funcionalistas vai além da estrutura gramatical, ou seja, está centrado também, e principalmente, nas circunstâncias discursivas que envolvem as estruturas linguísticas e seus contextos específicos de uso.

Assim, torna-se fácil perceber que as abordagens funcionais, ao contrário das perspectivas formalistas, preocupam-se

\begin{abstract}
com as relações (ou funções) entre a língua como um todo e as diversas modalidades de interação social, e não tanto com as características internas da língua; frisam, assim, a importância do papel do contexto, em particular do contexto social, na compreensão da natureza das línguas. (NEVES, 1997 p. 41).
\end{abstract}

Assim, reconhecendo a grande utilidade das abordagens funcionalistas dos itens gramaticais para o desenvolvimento da capacidade comunicativa dos alunos, foi iniciado, nas reuniões entre coordenadores e bolsistas, um estudo sobre as perspectivas formalista e funcionalista da linguagem como forma de respaldar a prática a ser desenvolvida pelos bolsistas em sala de aula.

Sob o rótulo de funcionalismo, contudo, reúnem-se perspectivas teóricas muito diversas. Prideaux (1994), por exemplo, afirma que, provavelmente, existem tantas versões do funcionalismo quantos linguistas que se chamam de funcionalistas, denominação que abrange desde os que simplesmente rejeitam o formalismo até os que criam uma teoria. Desse modo, optamos por trabalhar com a perspectiva funcionalista da linguística sistêmico-funcional, que busca identificar as estruturas de linguagem específica que contribuem para o significado de um texto. Segundo Webster (2009), as análises que se realizam nessa perspectiva teórica se propõem a mostrar como e por que um texto significa o que significa.

Segundo Halliday (1994), os usos que fazemos do sistema linguístico são funcionais relativamente às nossas necessidades de convivência em sociedade. Assim, na perspectiva hallidayana, ao usarmos a linguagem fazemos uma série de escolhas disponíveis no sistema linguístico para atender aos nossos propósitos comunicativos.

Com base nessa perspectiva, é fundamental desenvolvermos a consciência sobre os significados não só das palavras, mas também das estruturas gramaticais em textos para que nossos propósitos comunicativos sejam atingidos, pois também essas estruturas significam. Ao optar, por exemplo, por uma construção na voz passiva em detrimento 
de outra na voz ativa, significados são trazidos para o texto em termos de ênfase, possibilidade de apagamento do ator da ação expressa pelo grupo verbal, etc.

Assim, num primeiro momento, foram trabalhados alguns conceitos fundamentais para a teoria sistêmico-funcional tais como a noção de escolha, a relação de texto e contexto e as metafunções que a linguagem desempenha em interface com as variáveis contextuais.

De posse desse arcabouço teórico, que leva em conta a interação, os bolsistas estariam aptos a desenvolver atividades e estratégias de ensino que favorecessem o desenvolvimento da competência comunicativa dos alunos. E foi o que, de fato, ocorreu: as atividades de gramática passaram a apresentar outra orientação e o foco passou a ser o efeito discursivo de cada escolha de item gramatical em função do contexto.

Com base na perspectiva sistêmico-funcional, foram elaboradas várias atividades sobre diferentes itens gramaticais. A título de exemplificação, será apresentada, neste relato, a atividade-modelo sugerida aos bolsistas para que, com base nela, eles pudessem preparar o material didático a ser levado aos alunos da escolaparceira. O tema da atividade são os processos sintáticos de união de orações, tradicionalmente conhecidos como coordenação e subordinação. Nesse primeiro momento, não foi empregada a terminologia usada por Halliday para o período composto, a chamada oração complexa. Deu-se prioridade nesse momento à valorização da noção de escolha dentre as opções do reservatório de opções gramaticais, relacionando-as ao contexto de situação, conceito também trabalhado com os bolsistas. O discente é, assim, levado a reconhecer os significados subjacentes às diferentes escolhas realizadas.

De forma geral, nas aulas de língua portuguesa, os períodos compostos por coordenação e subordinação costumam ser tratados no âmbito exclusivamente formal, desconsiderando que o usuário da língua, ao lançar mão desses processos sintáticos de união de orações, faz isso com interesses essencialmente discursivos: ênfase em determinada ideia, relacionamento de tópicos diversos, ligação entre parágrafos; enfim, propósitos que vão além das abordagens estritamente formais dos períodos compostos expostas na maioria das gramáticas.

Além disso, especificamente em relação ao período composto por subordinação, é prática comum, em estudos gramaticais de orientação formalista, a ênfase na análise das orações subordinadas, quer quanto ao reconhecimento de suas funções - 
substantivas, adjetivas ou adverbiais -, quer quanto a sua estrutura - desenvolvidas ou reduzidas -, ou ainda quanto ao mecanismo de união de orações - conectivas ou justapostas. Pouco se diz, contudo, sobre os efeitos discursivos provocados pela opção entre coordenação ou subordinação para a construção de períodos compostos e tampouco se fala da disposição das orações no período, o que seria de fato o mais relevante para qualquer usuário da língua.

Com base no exposto, propomos aos bolsistas uma abordagem funcional da questão. Para isso, foi usado o texto de Sodré (1971), que se segue.

"A tevê, apesar de nos trazer uma realidade concreta, não fornece uma reprodução fiel da realidade. Uma reportagem de tevê, com transmissão direta, é o resultado de vários pontos de vista: do realizador, que controla e seleciona as imagens num monitor; do produtor, que poderá efetuar cortes arbitrários; do cameraman, que seleciona os ângulos de filmagem; finalmente de todos aqueles capazes de intervir no processo da transmissão. Por outro lado, alternando sempre os closes (apenas o rosto de um personagem no video, por exemplo) com cenas reduzidas (a vista geral de uma multidão), a televisão não dá ao espectador a liberdade de escolher entre o essencial ou o acidental, ou seja, aquilo que ele deseja ver em grandes ou pequenos planos. Dessa forma, a tevê impõe ao receptor a sua maneira especialíssima de ver o real." (Murilo Sodré, A comunicação do grotesco)

A análise proposta partiu do primeiro período do texto A tevê, apesar de nos trazer uma realidade concreta, não fornece uma reprodução fiel da realidade e da relação desse período com o contexto que o segue.

De modo geral, as abordagens dos livros didáticos acerca da coordenação e da subordinação valorizam apenas a identificação e classificação das orações do período em estudo, sem atentar para a relevância discursiva desses processos.

O nexo semântico presente no primeiro período do texto em análise poderia ser explicitado de outras formas, além daquela expressa no texto original. Partindo-se do princípio de que a ideia de oposição ou contraste tanto pode ser expressa por uma coordenada adversativa quanto por uma subordinada concessiva, analisamos algumas opções de estruturação:

I. A tevê, apesar de nos trazer uma imagem concreta, não fornece uma reprodução fiel da realidade.

II. Apesar de não fornecer uma reprodução fiel da realidade, a tevê nos traz uma imagem concreta. 
III. A tevê nos traz uma imagem concreta, mas não fornece uma reprodução fiel da realidade.

IV. A tevê não fornece uma reprodução fiel da realidade, mas nos traz uma imagem concreta.

Todas as estruturações acima foram apresentadas aos bolsistas e foram reconhecidas como aceitáveis, contudo, a partir do momento em que foi considerado o contexto, algumas limitações se impuseram. Uma leitura, mesmo que superficial do texto, permitiu perceber que o desenvolvimento do parágrafo apresentava argumentos favoráveis à tese de que a televisão não fornece uma reprodução fiel da realidade.

Desse modo, as opções II e IV tornavam-se opções incoerentes nesse contexto. Em II, a ideia de a tevê não fornecer uma reprodução fiel da realidade está na oração subordinada, o que lhe confere menor destaque. Ganha realce, nesse período, a ideia de que a televisão traz uma imagem concreta, que representa a oração principal.

Já em IV, o uso da conjunção coordenativa adversativa valoriza justamente o conteúdo da oração sindética, já que tudo que é enunciado depois do mas assume força retórica, ou seja, é favorável à tese que se quer defender. Assim, nesse período, a ideia que acompanha a conjunção adversativa - no caso o fato de a televisão trazer uma imagem concreta - ganha projeção no período.

Restam, assim, as opções I e III que, por sua estruturação sintática, dão relevo justamente à ideia que se quer defender no texto. A opção pela subordinação, contudo, é a mais adequada, uma vez que a desigualdade de valores semânticos encontra expressão mais adequada numa estrutura em que se evidencie também uma desigualdade de valores sintáticos.

Foi possível mostrar aos bolsistas, pelo breve exemplo, a grande importância que os processos de coordenação e subordinação têm para a estruturação dos textos em geral. Através deles, garante-se a ênfase adequada à ideia que se quer valorizar, mantendo-se a coerência do texto.

Demonstrou-se, assim, que o tratamento dado à questão dos processos sintáticos nos bancos escolares não têm permitido que tais processos sejam vistos como recursos à disposição do falante/escritor para que ele possa veicular, da melhor forma possível, os conteúdos que quer comunicar ao produzir seus textos.

A partir desse modelo, atividades com essa orientação foram replicadas pelos bolsistas e apresentadas aos professores supervisores da escola-parceira, que acolheram, 
de imediato, a proposta, ao perceberem o efeito que o tratamento de orientação funcional dos processos de coordenação e subordinação tem na construção dos textos.

Com base nesse tratamento dado ao ensino de gramática, foram iniciados alguns projetos de valorização da e estímulo à produção escrita do discente. Entre eles, o projeto Vozes da Argumentação, que tem como principal objetivo a análise e produção de textos argumentativos pertencentes a diferentes gêneros (editoriais, artigos de opinião, redações vestibulares, etc), tendo em vista, entre outros aspectos, as marcas linguísticas características desse tipo de texto.

O trabalho realizado no PIBID tem mostrado a urgência na mudança do tratamento dado ao ensino dos aspectos gramaticais na escola, de forma a desenvolver a competência comunicativa dos alunos e promover a tão esperada integração entre as diferentes áreas em que se divide o ensino de língua portuguesa, a saber, ensino de gramática, ensino de leitura e ensino de produção de textos.

Com base no que foi exposto, queremos crer que somente uma prática de ensino calcada no funcionamento textual-discursivo dos elementos da língua será capaz de desenvolver a competência linguística de nossos alunos, tornando-os cidadãos capazes de, por meio da leitura e da escrita, desenvolver seu papel social, uma vez que a língua funciona em textos que atuam em situações específicas de interação comunicativa e não em palavras e frases isoladas e abstraídas de qualquer situação ou contexto de comunicação.

Confirmamos, desse modo, as palavras de Travaglia (1996 p. 109), quando declara que "a perspectiva textual tem a possibilidade de fazer com que a gramática seja flagrada em seu funcionamento, evidenciando que a gramática seja a própria língua em uso." Só a partir dessa perspectiva, será possível mudar o conceito de gramática usado no ensino de língua portuguesa, dando o primeiro passo para a mudança efetiva da prática atual. Nesse sentido, vemos no PIBID a possibilidade de mudança real do quadro atual do ensino de língua portuguesa, de forma a torná-lo, de fato, produtivo.

\section{REFERÊNCIAS}

ABREU, A. S.. Curso de redação. São Paulo: Ática, 2004.

ANTUNES, I.. Muito além da gramática: por um ensino de língua sem pedras no caminho. São Paulo: Parábola, 2007. 
Aula de português: encontro e interação. São Paulo: Parábola, 2003.

BEAUGRANDE, R. A.; DRESSLER, W. U. Introduction to text linguistics. Londres: Longman, 1983.

GARCIA, O. M. Comunicação em prosa moderna. Rio de Janeiro: FGV, 1986.

HALLIDAY, M. A. K. Estrutura e função da linguagem. In: LYONS, J. (org.) Novos horizontes em lingüística. São Paulo: Cultrix, Ed. da Universidade de São Paulo, 1976.

An Introduction to Functional Grammar. $2^{\mathrm{a}}$. ed. London: Edward Arnold, 1994.

HALliDAY, M e HASAN, R. Language, Context and Text: Aspects of Language as a Social-Semiotic Perspective. Oxford University Press, 1989.

NEVES, M. H. M. N. A gramática funcional. São Paulo: Martins Fontes, 1997.

PRIDEAUX, G. D. Processing strategies: A psycholinguistic neo-functionalism? In: R. DIRVEN \& V. FRIED (eds). Functionalism in Linguistics. Amsterdam/Philadelphia: John Benjamim Publishing Company, 1987.

SARDINHA, T. B. Metáfora. São Paulo: Parábola, 2007.

TERRA, E. NICOLA, J. de. Português de olho no mundo do trabalho. São Paulo: Scipione, 2004.

TRAVAGLIA, L. C. Gramática e interação: uma proposta para o ensino de gramática no $1^{\circ}$ e $2^{\circ}$ graus. São Paulo: Cortez, 1996.

. Gramática: ensino plural. São Paulo: Cortez, 2003.

VAL, Maria da Graça. Redação e textualidade. São Paulo; Martins Fontes, 1999.

WEBSTER, J. Introduction. In: HALLIDAY, M. A. K. E WEBSTER, J. Continuum Companion to Systemic Functional Linguistics. Nova York: Continuum International Publishing Group, 2009.

\section{AAUTORA}

Magda Bahia Schlee possui graduação em Letras pela Universidade do Estado do Rio de Janeiro (1987), mestrado em Letras (Letras Vernáculas) pela Universidade Federal do Rio de Janeiro (1994) e doutorado em Letras pela Universidade do Estado do Rio de Janeiro (2008). É professora adjunta da Universidade do Estado do Rio de Janeiro. Tem experiência na área de Letras, atuando principalmente nos seguintes temas: sintaxe, linguística sistêmico-funcional, produção textual, ensino-aprendizagem. Atualmente, é uma das coordenadoras do PIBID/UERJ - subprojeto de Língua Portuguesa.

E-mail: magdabahia@globo.com 